\title{
Custos no serviço público: o sistema gerencial de custos do exército
}

\author{
Mestrado em Administração pela Pontifícia Universidade Católica do Paraná - PUCPR \\ Rua Imaculada Conceição, 1155. Prado Velho. Curitiba/PR. CEP: 80215-901 \\ E-mail: moacircarneirojunior@yahoo.com.br
}

Wesley Vieira da Silva Doutorado em Engenharia de Produção pela Universidade Federal de Santa Catarina UFSC Coordenador do Programa de Pós-Graduação Stricto Sensu em Administração na Pontifícia Universidade Católica do Paraná - PUCPR Rua Imaculada Conceição, 1155. Prado Velho. Curitiba/PR. CEP: 80215-901 E-mail: wesley.vieira@pucpr.br

Daniela Torres da Rocha Doutorado em andamento em Administração pela Pontifícia Universidade Católica do Paraná - PUCPR Rua Imaculada Conceição, 1155. Prado Velho. Curitiba/PR. CEP: 80215-901 E-mail: danitorres.rocha@gmail.com

\section{RESUMO}

A Lei de Responsabilidade Fiscal trouxe a obrigatoriedade da apuração de custos pela Administração Pública. Para dar uma contribuição ao cumprimento da lei, este artigo tem como objetivo identificar o método de custeio mais adequado para apuração de custos no setor público. Para atingir o objetivo, abordam-se os principais métodos de custeio, quais sejam: Custeio por Absorção, Custeio Direto e Custeio Baseado em Atividades, apresentando-se as vantagens e desvantagens de cada um. A preocupação do governo federal com relação à apuração de custos foi apresentada no item que discorre sobre a Comissão Interministerial de Custos. Para melhor ilustrar o tema abordado, apresenta-se o método de custeio na Administração Pública Federal, mais precisamente no exército brasileiro.

Palavras-chave: Custos. Métodos de Custeio. Administração Pública.

Costs in public service: the cost management system of army. 


\section{ABSTRACT}

The Brazilian Fiscal Responsibility Law brought the obligation of the assessment of costs by the Public Administration. To make a contribution to the rule of law, this article aims to identify the most appropriate method of funding for assessment of costs in the public sector. To achieve the goal, touched up the main methods of funding, namely, Costs by Absorption, Direct Costs and Activities Based Costs, presenting the advantages and disadvantages of each. The concern of the federal government with respect to the assessment of costs was presented in the item that discusses the Interministerial Commission of costs. To better illustrate the subject matter, it is presented the method of costing in the Federal Public Administration.

Key-words: Costs. Methods of cost. Public Administration.

\section{INTRODUÇÃO}

No atual cenário, onde os recursos financeiros estão cada vez mais escassos, torna-se imprescindível que as organizações aperfeiçoem os seus processos buscando ferramentas que auxiliem na tomada de decisão, criando indicadores que permitam avaliar seu desempenho. Novos instrumentos de gestão devem ser incorporados a fim de dotar os administradores de maior capacidade gerencial. Na administração pública essa preocupação também está presente, seja em função da legislação, seja pela exigência da sociedade.

Um dos principais indicadores de desempenho é a apuração dos custos dos serviços. Embora a gestão de custos não se constitua em uma prática na Administração Pública Federal, alguns órgãos merecem destaque, tais como o Comando da Aeronáutica, Organizações Militares Prestadoras de Serviços (OMPS) do Comando da Marinha, Sistema Gerencial de Custos (SISCUSTOS) do Comando do Exército, Conselho Nacional de Desenvolvimento Científico e Tecnológico (CNPq), Secretaria de Educação Superior do Ministério da Educação (SESu-MEC), Banco Central, Instituto Nacional de Metrologia, Normalização e Qualidade Industrial (Inmetro), Empresa Brasileira de Pesquisa Agropecuária (EMBRAPA) entre outros (COMISSÃO INTERMINISTERIAL DE CUSTOS, 2006). 
Com o advento da Lei de Responsabilidade Fiscal (LRF), Lei Complementar n. 101 , de 4 de maio de 2000, os governos foram obrigados a demonstrar como aplicam os recursos arrecadados. Aliado a isso, a sociedade de modo geral busca a transparência dos atos governamentais, com o intuito de saber como está sendo gasto o dinheiro recolhido por meio de tributos. Porém, são apresentados apenas demonstrativos dos recursos arrecadados e aplicados, sem retratar o custo efetivo de cada programa governamental. Nos dias atuais são apresentados diversos métodos de custeio, sendo os mais usuais o Custeio por Absorção, o Custeio Direto e o Custeio Baseado em Atividades ( $A B C$ ). Diante deste cenário, pergunta-se: Qual o método de custeio mais adequado para mensurar os custos da Administração Pública? Como objetivo geral tem-se: identificar o método de custeio mais adequado para a apuração dos custos no setor público.

No que tange à apuração de custos pela Administração Pública Direta no Brasil, não se observa a mesma cultura e aprimoramento utilizado pela iniciativa privada. Porém, com o advento da Lei de Responsabilidade Fiscal, o assunto "custos" passou a figurar nas discussões no âmbito público, pois o texto legal no seu artigo cinqüenta, parágrafo terceiro, determina que "A Administração Pública manterá sistema de custos que permita a avaliação e o acompanhamento da gestão orçamentária, financeira e patrimonial". Diante do exposto, considera-se que este trabalho se justifica, pois aborda os conceitos de custos e verifica a viabilidade de sua utilização no setor público.

\section{REFERENCIAL TEÓRICO}

\subsection{Custos - História e Conceito}

Segundo Martins (2001, p. 23), "Contabilidade de Custos nasceu da Contabilidade Financeira, quando da necessidade de avaliar estoques na indústria, tarefa essa que era fácil na empresa típica da era do mercantilismo".

Mattos (2008) expõe que o desenvolvimento e o emprego de máquinas na produção fizeram surgir novos custos, exigindo métodos mais complexos para medi-los. 
A complexidade destes métodos, capazes de solucionar cada vez com mais rapidez os custos de fabricação, originou a contabilização dos custos.

O mesmo autor salienta, ainda, que a partir da Io Guerra Mundial surgiu a necessidade de aperfeiçoar os mecanismos de planejamento e controle das empresas, devido ao incremento do processo produtivo, ao aumento da concorrência entre empresas e a escassez de recursos. Neste sentido as informações de custos, apresentadas em relatórios, serviriam de subsídio para o controle e planejamento empresarial. Assim, a contabilização dos custos tornou-se um importante sistema de informações gerenciais.

De acordo com Martins (2001, p. 22), instituições não industriais, tais como instituições financeiras, empresas comerciais, firmas de prestação de serviço etc., passaram a explorar o potencial da Contabilidade de Custos para controle e tomada de decisões. Aproveitando-se deste enunciado de Martins, pode-se deduzir que a Contabilidade de Custos também pode ser aplicada no setor público.

\subsection{Métodos de Custeio}

Dos diversos métodos de custeio existentes, são apresentados o Custeio por Absorção, o Custeio Direto ou Variável e o Custeio Baseado em Atividades (ABC), por serem os mais usuais e amplamente abordados na literatura sobre custos.

\subsubsection{Custeio por Absorção}

Para Martins (2001, p. 41), o Custeio por Absorção "Consiste na apropriação de todos os custos de produção aos bens elaborados, e só os de produção. Todos os gastos relativos ao esforço de fabricação são distribuídos para todos os produtos feitos".

O Custeio por Absorção é utilizado para a avaliação dos estoques. É apropriado para entidades cujos custos diretos são de maior relevância que os custos indiretos, pois estes dependem de rateio para alocação ao produto.

Martins (2001, p. 61) apresenta o esquema básico do Custeio por Absorção, qual seja: 
a) separação entre custo e despesa;

b) apropriação dos custos diretos diretamente aos produtos; e

c) rateio dos custos indiretos.

A Figura 1 ilustra a lógica contábil subjacente do Custeio por absorção:

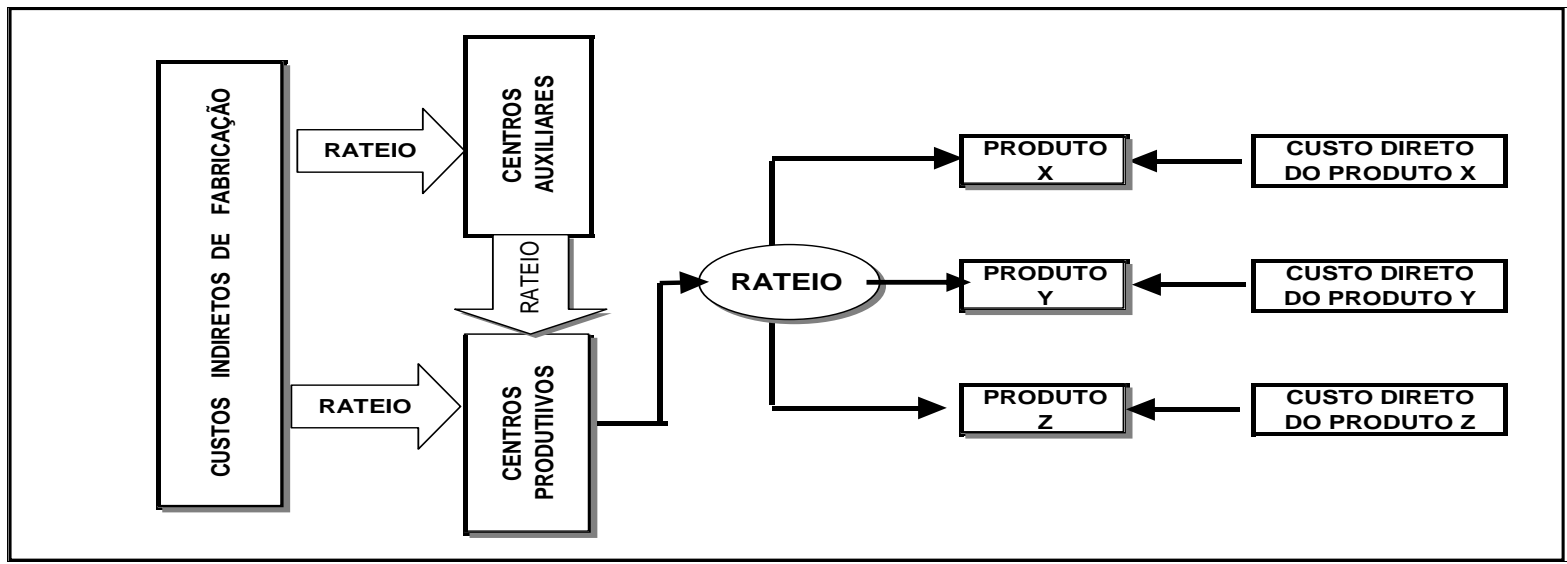

Figura 1 - Lógica contábil subjacente do Custeio por Absorção Fonte: Souza et al. (2003 apud CARNEIRO JUNIOR, 2006).

O Custeio por Absorção apresenta como vantagem a aceitação pelo fisco brasileiro para fins do Imposto de Renda. Também comunga com o Princípio Contábil da Competência, pois reconhece os custos de produção por ocasião da venda, demonstrando de forma apropriada a confrontação das despesas e receitas na apuração do resultado (ANDRADE et al., 2006).

Como desvantagem do Custeio por Absorção, apresenta-se a sua limitação para prestar informações. Martins (2001, p. 214) ainda aponta o rateio do custo fixo como grande problema do custeio por absorção, devido à arbitrariedade com que se faz esse rateio, o custo do produto pode não ser fielmente representado, levando produtos deficitários a apresentar bons resultados e produtos superavitários a serem descartados da linha de produção, por serem considerados deficitários. 


\subsubsection{Custeio Direto}

Com o intuito de amenizar o problema dos rateios dos Custos Indiretos foi criado o Custeio Direto ou Custeio Variável, no qual tão somente os custos variáveis são alocados aos produtos, os custos fixos são tratados como despesas (MARTINS, 2001, p. 215).

O Custeio Direto não é aceito pelo fisco, porque fere os Princípios Contábeis da Competência e da Confrontação, pois apropria todos os custos fixos antes da realização das vendas (MARTINS, 2001, p. 220).

Para o Custeio Direto são importantes os conceitos de margem de contribuição e ponto de equilíbrio. A margem de contribuição é a diferença entre o preço de venda e a soma dos custos variáveis. Porém, segundo Martins (2001, p.226), esse conceito não é completo, pois, para o cálculo da margem, devem ser consideradas todas as despesas variáveis. Segundo Martins (2001, p. 273), "o Ponto de Equilíbrio [...] nasce da conjugação dos custos totais com as receitas totais". Em resumo, o ponto de equilíbrio é a quantidade de produtos produzidos e vendidos para pagar seus custos e despesas fixas. A Figura 2 apresenta a lógica subjacente ao Custeio Direto:

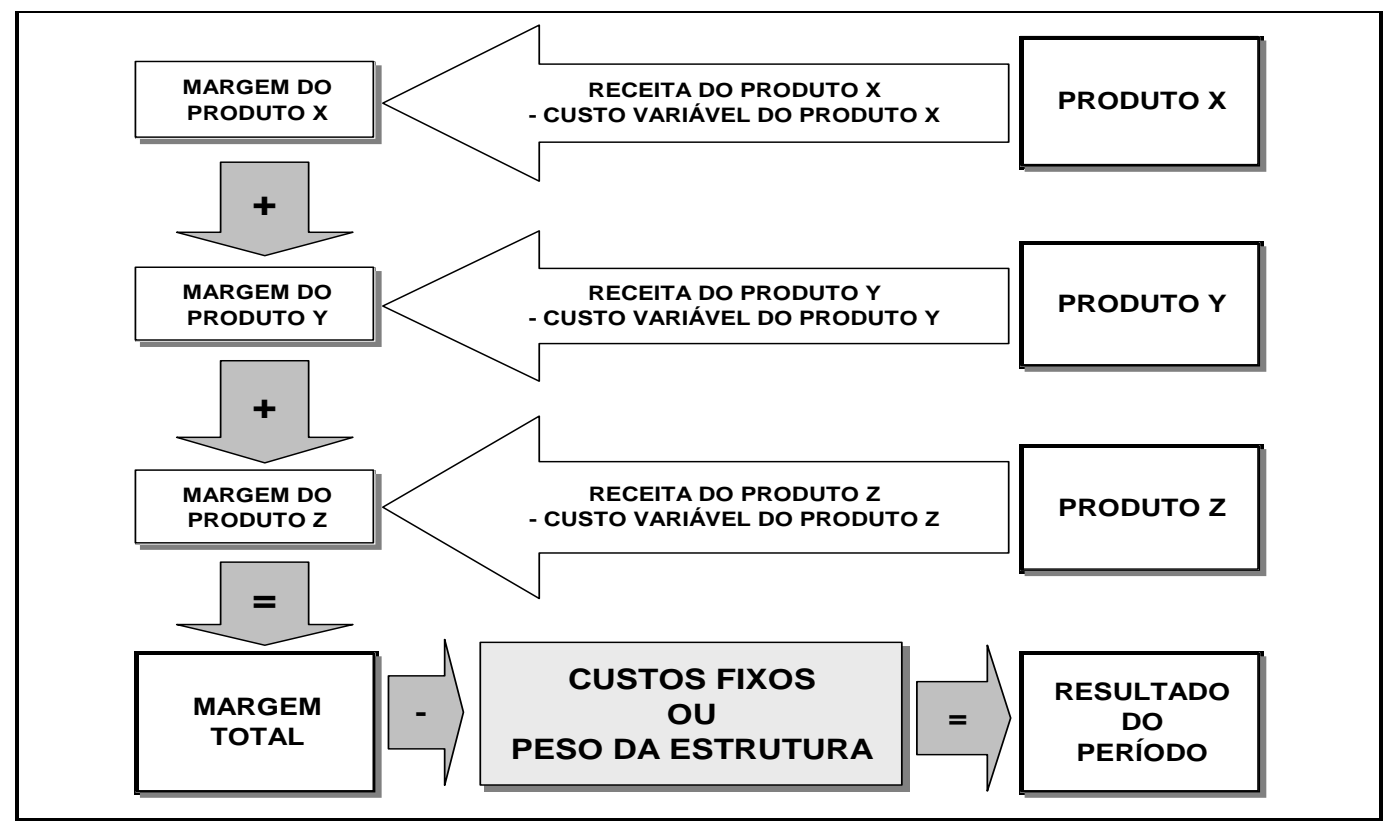

Figura 2 - Lógica subjacente ao Custeio Direto

Fonte: Souza et al. (2003 apud CARNEIRO JUNIOR, 2006). 
Algumas vantagens e desvantagens do Custeio direto são apresentadas a seguir, conforme Padoveze (2003 apud CARNEIRO JUNIOR, 2006):

Vantagens:

- Os custos dos produtos são mensuráveis objetivamente, pois não sofrerão processos arbitrários ou subjetivos de distribuição dos custos comuns;

- O lucro líquido não é afetado por mudanças de incremento ou diminuição de inventários;

- O dado necessário para a análise da relação custo-volume-lucro é rapidamente obtido do sistema de informação contábil;

- O Custeamento Direto é totalmente integrado com o Custo-Padrão e o Orçamento Flexível, possibilitando o correto controle de custos;

- Possibilita mais clareza no planejamento do lucro e na tomada de decisões.

Desvantagens:

-A exclusão do custo fixo indireto para valoração dos estoques causa sua subavaliação, fere os princípios contábeis e altera o resultado do período;

- Na prática, a separação de custos fixos e variáveis não é tão clara como parece, pois existe custos semivariáveis e semifixos, podendo o custeamento direto incorrer em problemas semelhantes de identificação dos elementos de custeio;

- O Custeamento Direto é um conceito de custeamento e análise de custos para decisões de curto prazo, mas subestima os custos fixos, que são ligados à capacidade de produção e de planejamento de longo prazo, podendo trazer problemas de continuidade para a empresa.

\subsubsection{Custeio Baseado em Atividades (ABC)}

Martins (2001, p. 93) explica que "o Custeio Baseado em Atividades, conhecido como ABC (Activity-Based Costing) é uma metodologia de custeio que procura reduzir sensivelmente as distorções provocadas pelos rateio arbitrário dos custos indiretos, [...]" 
$\mathrm{O}$ autor distingue o Custeio $\mathrm{ABC}$ em duas gerações. A primeira com uma visão exclusivamente funcional e de custeio de produto, que também oferece subsídios para atender às exigências legais com menor arbitrariedade no tratamento dos custos indiretos. Para Martins (2001, p.94), a segunda geração do $A B C$ não se limita ao custeio do produto, mas serve para fins gerenciais e estratégicos. Em ambas as gerações o enfoque do custeio são as atividades relevantes exercidas na empresa.

A atividade é definida por Martins (2001, p. 100) como "[...] uma combinação de recursos humanos, materiais, tecnológicos e financeiros para se produzirem bens ou serviços. É composto por um conjunto de tarefas necessárias ao seu desempenho. As atividades são necessárias para a concretização de um processo, que é uma cadeia de atividades correlatas inter-relacionadas".

A estruturação do Sistema de Informação da empresa para aplicação do ABC deve ser ajustada. Tradicionalmente a menor célula de acumulação de dados é Centro de Custo (Departamento). No ABC, o centro de custo deverá ser detalhado em Atividades como sub-centros de custos (PADOVEZE, 2003).

A Figura 3 ilustra tal situação:

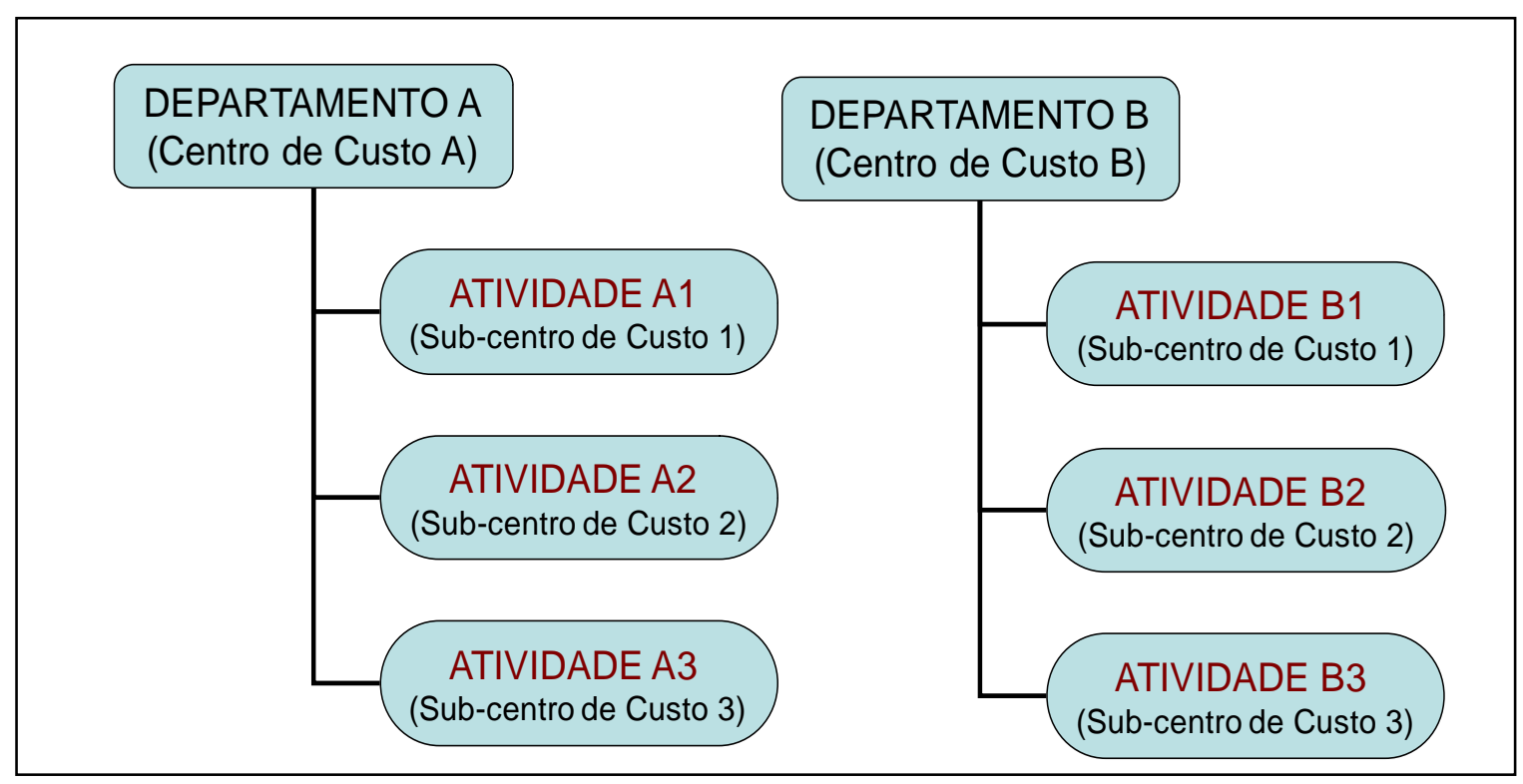

Figura 3 - Centros de custos e Subcentros de custos no ABC Fonte: Os autores 
Um novo conceito inserido pelo $A B C$ é o rastreamento, cuja definição é dada por Martins (2001, p. 104) como "uma alocação com base na identificação da relação causa e efeito entre a ocorrência da atividade e a geração dos custos". A relação causa-efeito é determinada por direcionadores, cujo conceito e aplicação serão descritos posteriormente.

Martins (2001, p. 104) distingue dois tipos de direcionadores, os de primeiro estágio, chamados de "direcionadores de recursos" e os de segundo estágio, chamados de "direcionadores de atividades". O primeiro serve para custear as atividades, pois identifica como as atividades consomem recursos. O segundo serve para custear os produtos, pois identifica como os produtos "consomem" atividades.

Como vantagens e desvantagens deste método de Custeio têm-se:

Vantagens:

- Mapeamento de todos os processos da empresa e melhor visualização dos fluxos dos processos;

- Melhor adequação às empresas de serviços, pela dificuldade de definição do que seja custos, gastos e despesas nessas entidades podendo ser empregado em diversos tipos de empresas (industriais, comerciais, de serviços, com ou sem fins lucrativos);

- Atende aos Princípios Fundamentais de Contabilidade (similar ao custeio por absorção);

- Obriga a implantação, permanência e revisão de controles internos;

- Identifica, de forma mais transparente, onde os itens em estudo estão consumindo mais recursos;

- Identifica o custo de cada atividade em relação aos custos totais da entidade;

- Pode, ou não, ser um sistema paralelo ao sistema de contabilidade;

- Possibilita a eliminação ou redução das atividades que não agregam valor ao produto.

Desvantagens:

- Gastos elevados para implantação; 
- Alto nível de controles internos a serem implantados e avaliados;

- Necessidade de revisão constante;

- Leva em consideração muitos dados;

- Informações de difícil extração;

- Dificuldade de envolvimento e comprometimento dos empregados da empresa;

- Necessidade de reorganização da empresa antes de sua implantação;

- Dificuldade na integração das informações entre departamentos;

- Falta de pessoal competente, qualificado e experiente para implantação e acompanhamento;

- Necessidade de formulação de procedimentos padrões; e

- Maior preocupação em gerar informações estratégicas do que em usá-las.

\subsection{Comissão Interministerial de Custos}

A apuração de custos na Administração Pública Federal é incipiente, aparecendo apenas algumas iniciativas isoladas por parte de poucos órgãos. Porém, a preocupação com a qualidade dos gastos do governo federal levou à criação da "Comissão Interministerial de Custos", instituída pela Portaria Interministerial $n^{\circ} 945$, de 26 de outubro de 2005, cujo objetivo, definido em seu primeiro artigo, é "elaborar estudos e propor diretrizes, métodos e procedimentos, para subsidiar a implantação do sistema de custos na Administração Pública Federal".

No decorrer dos trabalhos, a Comissão convidou órgãos da Administração Pública Federal que já possuem sistema de custos, concluído ou em desenvolvimento, para fazer a apresentação do sistema. Entre as apresentações foi exposto o Sistema Gerencial de Custos do Exército (SISCUSTOS), que na época estava em fase de desenvolvimento, haja vista que sua implantação está prevista para o ano de 2008, como será comentado posteriormente.

De acordo com o relatório final da Comissão, a expectativa é que o sistema de custos em âmbito federal contribua para o melhor aproveitamento dos recursos públicos, especialmente no contexto de restrição fiscal do Estado. Outros benefícios da 
apuração de custos, também citados no relatório, são "otimização dos resultados dos programas governamentais, maior qualidade e maior transparência do gasto público, redução do desperdício, aprimoramento da qualidade do produto oferecido ao cidadão, aperfeiçoamento da gestão pública e melhor desempenho institucional".

Ainda em relação ao relatório final da Comissão, é oportuno citar, resumidamente, as diretrizes recomendadas:

1. Gestão de Custos com foco no desempenho: "A Gestão de Custos, instrumentalizada pelos Indicadores de Custos e de Resultados, tem por finalidade otimizar o desempenho global das organizações e programas governamentais. Abrangência: todos os órgãos e entidades federais.

2. Gradualismo: implantação em três etapas:

1 a etapa - definição de padrões mínimos para apuração de um conjunto básico de indicadores para toda Administração Pública Federal; 2ª etapa - elaboração de projetos de sistemas de custos sob responsabilidade dos próprios órgãos e entidades; 3a etapa - implantação dos projetos de sistema de custos e consolidação do modelo de gestão baseado em custos e resultados.

3. Flexibilidade: todos os órgãos e entidades têm liberdade para:

- Escolha do método de custeio;

- Definição dos objetos de custeio, itens de custo, centros de custo, cost

drivers, critérios de rateio, entre outros; e

- Definição das rotinas operacionais.

4. Institucionalização: recomendável à criação de um Órgão Central de Custos.

5. Capacitação permanente: "O Poder Executivo Federal promoverá amplo programa de capacitação em mensuração e gestão de custos, de modo a constituir, no menor prazo possível, um quantitativo expressivo de pessoal qualificado e a consolidar uma cultura de custos na Administração Pública Federal".

6. Gestão do conhecimento: "As atividades vinculadas à criação, armazenamento e difusão do conhecimento em mensuração e gestão de custos receberão prioridade na implantação da Política de Custos". 
Custos no serviço público: o sistema gerencial de custos do exército Moacir Carneiro Junior, Wesley Vieira da Silva, Daniela Torres da Rocha

O relatório final da Comissão apresenta outras recomendações, cujo teor não se aplica ao escopo deste estudo.

\subsection{Sistema Gerencial De Custos Do Exército - Siscustos ${ }^{1}$}

A preocupação com a apuração de custos no Exército vem de longa data e está explícito no mapa estratégico da Secretaria de Economia e Finanças (SEF), órgão de direção setorial do Exército responsável pela execução orçamentária, administração financeira, contabilidade e controle interno da instituição, conforme apresentado na Figura 4:

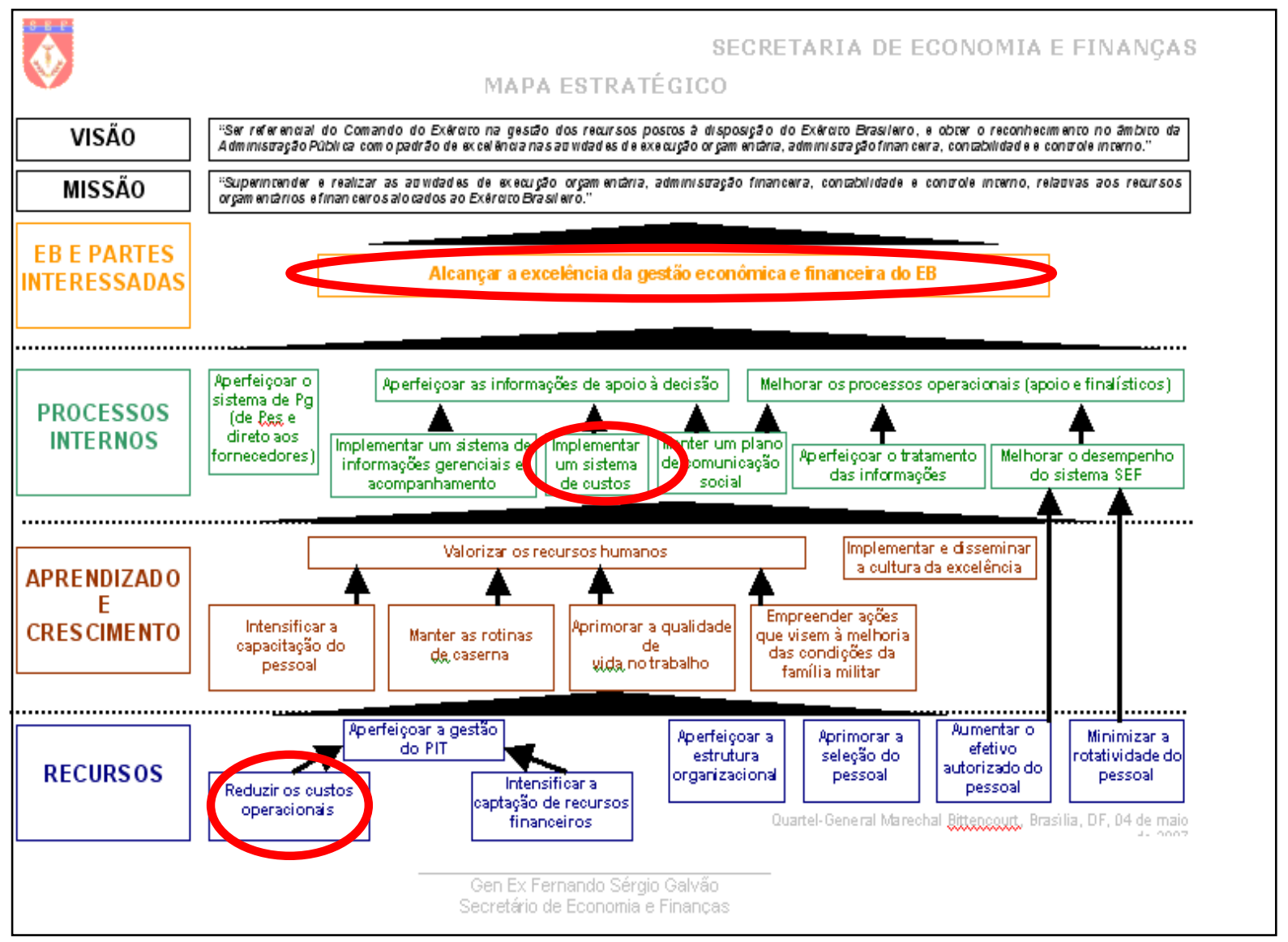

Figura 4 - Mapa estratégico da Secretaria de Contabilidade e Finanças do Exército Fonte: Exército Brasileiro - Secretaria de Economia e Finanças.

1 MINISTÉRIO DA DEFESA/EXÉRCITO BRASILEIRO. Estágio de Custos. Curso presencial. Brasília: MINISTÉRIO DA DEFESA/EXÉRCITO BRASILEIRO, 2007. 
A implantação de um sistema de custos no Exército é justificada porque a instituição necessita:

- Identificar os insumos que contribuem para os resultados alcançados na execução das atividades (rotinas) das Organizações Militares (OM).

- Avaliar o montante de recursos consumidos em cada atividade.

- Identificar quais atividades agregam valor ao resultado final das ações a cargo dos Órgãos Gestores.

- Buscar a eficiência, a eficácia e a efetividade na aplicação dos recursos.

\subsubsection{Histórico do SISCUSTOS}

À Diretoria de Contabilidade (D Cont), subordinada à SEF, coube a missão de desenvolver e implantar o sistema de custos do Exército.

No início dos trabalhos, em 2004, a D Cont identificou as dificuldades para implantação do sistema, considerando-as desafios para sua concepção:

- Criar um sistema gerencial de custos que possibilitasse compatibilizar a linguagem da Contabilidade Pública com os sistemas corporativos em uso no Exército;

- Estabelecer uma metodologia que gerasse custos em função das atividades que o Exército executa.

Para melhor desenvolvimento dos trabalhos, foram estabelecidas diretrizes para a modelagem do sistema, cujo teor é abaixo apresentado:

- Simplicidade;

- Informações com propósitos definidos;

- Uso da tecnologia como ferramenta;

- Dados extraídos diretamente do SIAFI e de outros sistemas corporativos em uso no Exército;

- Evitar retrabalho;

- Foco no cliente (todas Organizações Militares do Exército);

- Atenção às peculiaridades e às necessidades de cada Órgão Gestor; 
- Participação e comprometimento dos Órgãos Gestores e demais Organizações Militares;

- Enfoque Gerencial, com o objetivo de identificar as atividades que consomem recursos e que resultam na consecução de um produto ou de um serviço;

- Modelagem dinâmica;

Observando as necessidades do Exército e seguindo as diretrizes estabelecidas, foram determinados os objetivos do sistema, quais sejam:

- Identificar o custo das atividades do Comando do Exército.

- Proporcionar aos tomadores de decisão, nos seus respectivos níveis, informações gerenciais sobre os custos apropriados nas diferentes atividades.

- Realizar o acompanhamento gerencial das Organizações Militares.

- Disponibilizar informações, em tempo hábil, para auxiliar no processo decisório, mediante a análise comparativa dos custos reais com os custos padrões.

\subsubsection{Escolha do Sistema de Custeio}

Uma grande dificuldade enfrentada pelo Exército é a complexidade de atividades desenvolvidas pelas diversas Organizações Militares, pois as unidades desempenham atividades específicas, de acordo com sua missão dentro da força. Como exemplo, pode-se citar as unidades operacionais (batalhões de infantaria e de engenharia de combate, regimentos de cavalaria e grupos de artilharia), unidades de saúde (hospitais e policlínicas militares), unidades de logística e manutenção (batalhões logísticos e de suprimento, parques de manutenção e arsenais de guerra), além de Órgãos Gestores de recursos, unidades de caráter administrativo e de controle interno.

Com base nessas características, o Exército optou pelo método de custeio $A B C$, por ser o mais adequado às suas peculiaridades, compactuando, assim, com a doutrina existente sobre apuração de custos no setor público.

\subsubsection{Conceito e Definição do SISCUSTOS}

Com o intuito de se adequar à legislação vigente e de aprimorar o gerenciamento de seus recursos, o Exército criou o Sistema Gerencial de Custos do Exército 
(SISCUSTOS), cuja definição é dada como "um sistema gerencial, integrado a outros sistemas corporativos do Exército, que tem por finalidade proporcionar aos gestores das Organizações Militares (OM) informações relevantes sobre os custos dos produtos e serviços produzidos por essas OM".

Pela sua concepção, o SISCUSTOS tem como objetivo se constituir em uma ferramenta organizacional de todo o Exército. Em uma primeira instância, servirá para aperfeiçoar a capacidade gerencial da instituição, cujo reflexo será a melhoria da capacidade operacional da força. Enfim, com seu enfoque gerencial, o SISCUSTOS visa identificar as atividades que consomem recursos e que resultam na consecução de um produto ou de um serviço.

\subsubsection{Ideia Global do Sistema}

A proposta do SISCUSTOS é proceder ao levantamento dos custos até o nível "programa de governo". Para isso, cada projeto ou atividade poderá dar origem a vários Grupos de Custos (GC), que, por sua vez, poderá se subdividir em tantos Centros de Custos quanto necessários.

A seguir, a Figura 5 apresenta o esquema que torna mais fácil a visualização da idéia global do sistema (SISCUSTOS - Manual do Usuário 2007): 


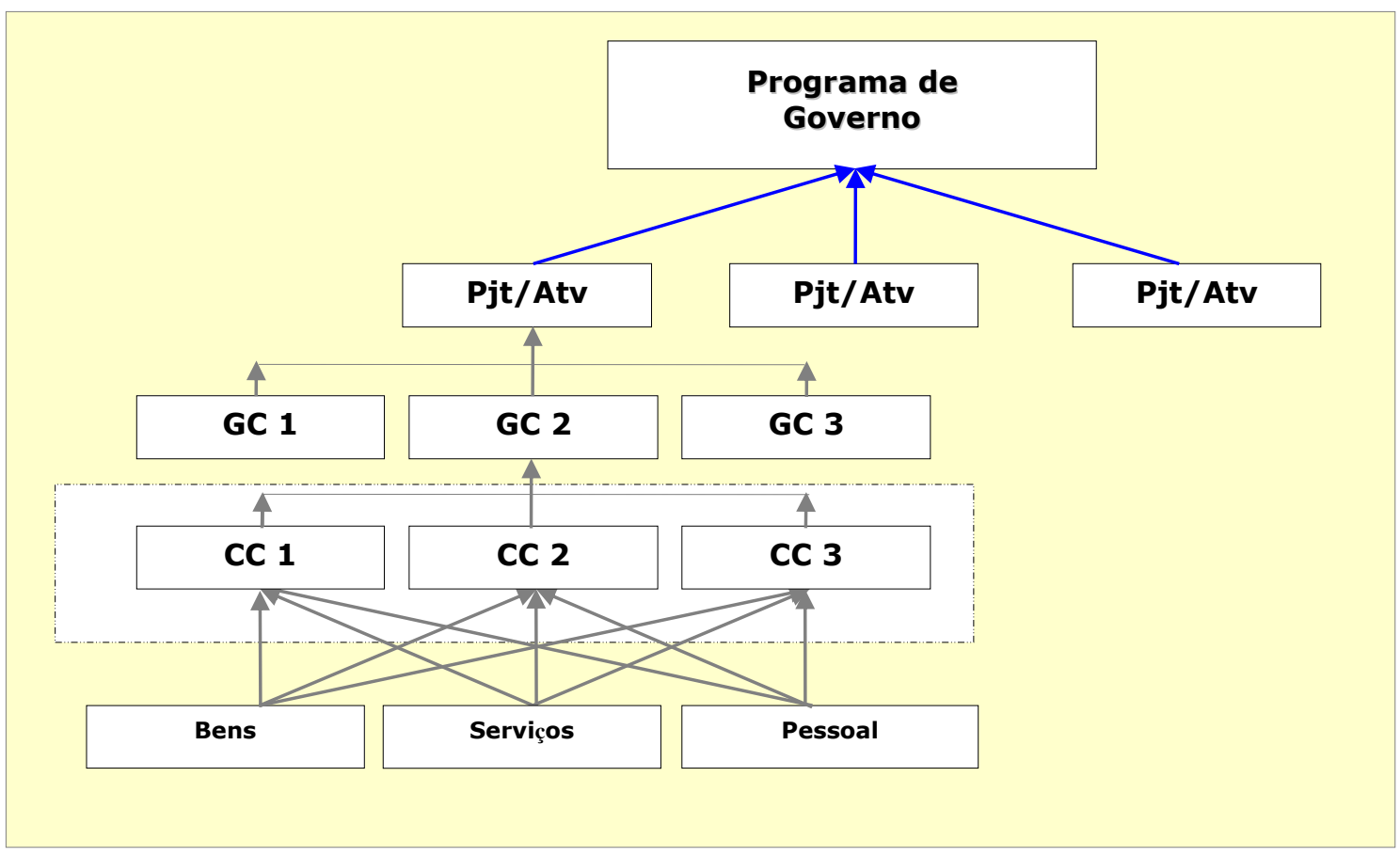

Figura 5 - Idéia Global do Sistema

Fonte: Exército Brasileiro - Diretoria de Contabilidade.

Nota: GC = Grupo de Custos $\mathrm{CC}=$ Centro de Custos

\subsubsection{Interação com Outros Sistemas Corporativos}

Como foi apresentado na definição, o SISCUSTOS está integrado a outros sistemas corporativos, cujo objetivo é fornecer os dados para apuração dos custos, sem gerar retrabalho. A importação dos dados está a cargo da Diretoria de Contabilidade ( $D$ Cont), que fará uso da tecnologia da informação para captar os dados que alimentarão o sistema.

Os sistemas corporativos que alimentarão o SISCUSTOS são os seguintes (SISCUSTOS - Manual do Usuário, 2007):

- Sistema Integrado de Administração Financeira (SIAFI): sistema gerenciado pelo Serviço Federal de Processamento de Dados (SERPRO) que alimentará o SISCUSTOS com os custos dos serviços a serem apropriados pela Organização Militar;

- Sistema de Material do Exército (SIMATEx): os custos dos materiais devem ser apropriados quando consumidos, Então SISCUSTOS buscará os dados no 
SIMATEx, sistema desenvolvido pelo Centro Integrado de Telemática do Exército (CITEx) e gerenciado pelo Departamento Logístico, que tem como identificar o centro de custos para o qual está saindo os materiais, propiciando sua correta apropriação.

- Sistema Integrado de Administração de Recursos Humanos (SIAPE) e Sistema Automático de Pagamento de Pessoal (SIAPPES): os custos com pessoal no país são importados do SIAPE e do SIAPPES, que, respectivamente, processam o pagamento do pessoal civil e militar. A responsabilidade pela disponibilização destas informações é do Centro de Pagamento do Exército (CPEx).

- Sistema de Retribuição no Exterior (SRE): sistema corporativo gerenciado pelo Departamento Geral do Pessoal, fornece o custo com pessoal em serviço no exterior.

Às Organizações Militares cabe alocar aos centros de custos, diretamente no SISCUSTOS, o pessoal, a distribuição da carga energética e a identificação dos telefones instalados.

A Figura 6 apresenta graficamente o planejamento macro descrito: 


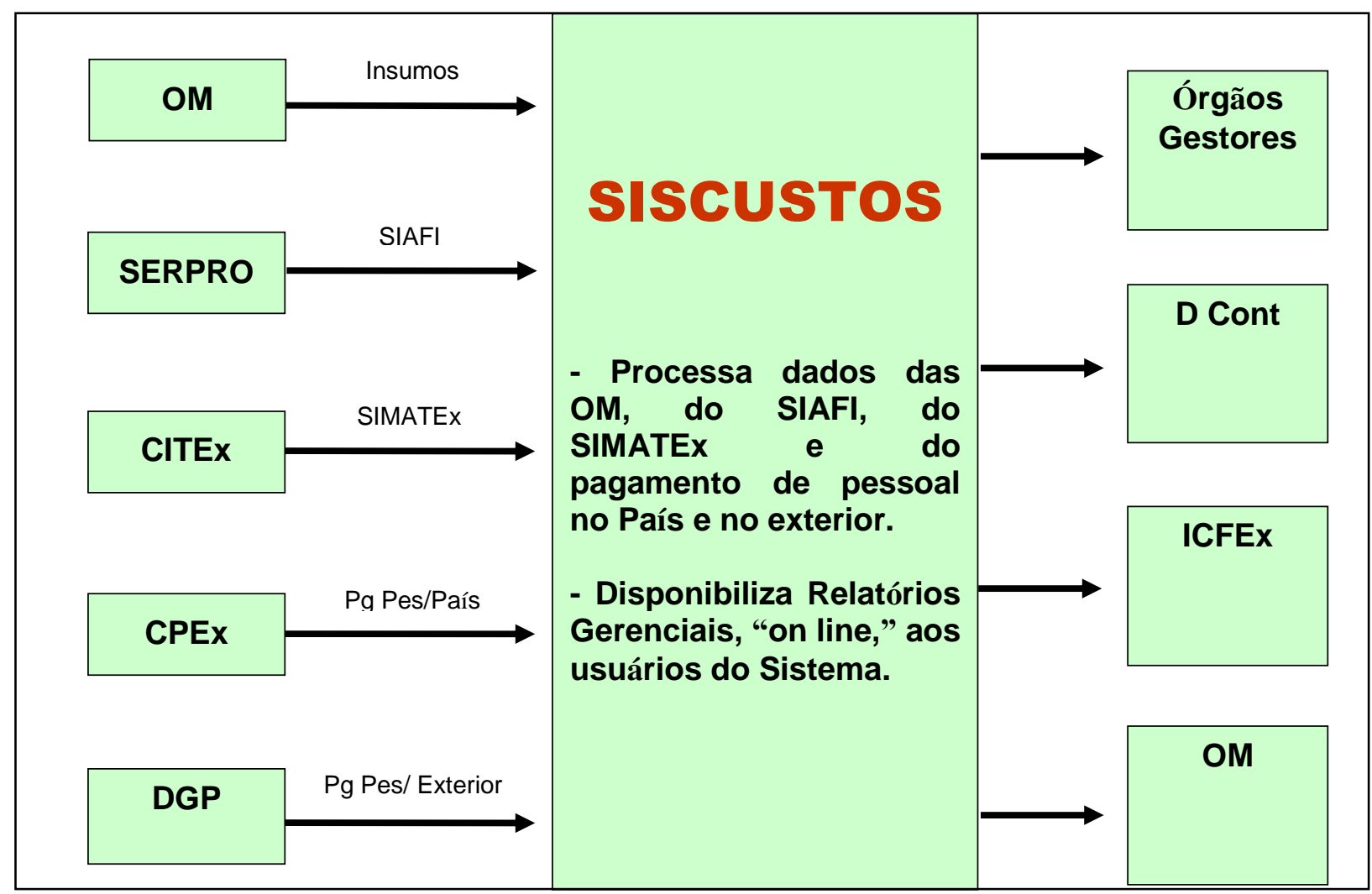

Figura 6 - Planejamento Macro

Fonte: Diretoria de Contabilidade

\section{CONSIDERAÇÕES FINAIS}

No contexto atual, onde se busca a competitividade e a qualidade de produtos e serviços, a apuração de custos torna-se fundamental em qualquer organização como ferramenta para a tomada de decisão. No setor público, além da busca de resultados, também há exigência legal, principalmente após a Lei de Responsabilidade Fiscal, a qual estabeleceu a obrigatoriedade da Administração Pública apurar custos, com o objetivo de permitir a avaliação e o acompanhamento da gestão orçamentária, financeira e patrimonial.

Visando à identificação do método de custeio mais adequado para a apuração dos custos no setor público, foram apresentados os principais métodos de custeio, fazendose a análise das vantagens e desvantagens de cada um. 
Inicialmente, apresentou-se um pequeno histórico dos custos, cujo surgimento se deu com o início do capitalismo, devido à necessidade de avaliar quanto custava cada bem produzido. Com o passar do tempo, surgiram diversos métodos de custeio, adequados à realidade histórica e à atividade de cada entidade. Atualmente a avaliação de custos não serve apenas para avaliar estoques, mas também se constitui uma ferramenta de gerenciamento e suporte para tomada de decisão.

Dos diversos métodos de custeio existentes, este trabalho abordou sinteticamente os mais usuais, quais sejam, Custeio por Absorção, Custeio Direto ou Variável e Custeio Baseado em Atividades (ABC).

Por fim, foi apresentado um exemplo concreto de sistema de custos na Administração Pública Federal, o Sistema Gerencial de Custos do Exército (SISCUSTOS), cujo método utilizado é o ABC. O desenvolvimento do SISCUSTOS teve início em 2004 e com implantação prevista para o ano de 2008.

Do exposto e levando-se em consideração que os serviços prestados pelos órgãos da Administração Pública são complexos e heterogêneos, deduz-se que muito ainda tem-se que evoluir em termos de Método de Custeio que atenda especificadamente as necessidade e especificidades do Serviço Público. Contudo, atualmente o método de custeio que sugere ser o mais indicado para a apuração dos custos do setor público $A B C$. Entre as causas desta indicação, está o fato de que o $A B C$ explora as especificidades de cada instituição, adaptando-se às mais diversas realidades, características que os outros métodos pesquisados não contemplam e ainda outro aspecto diz respeito aos custos indiretos, cuja participação no total dos custos do setor público é extremamente relevante e sua alocação arbitrária pode levar a tomada de decisões equivocadas. Como o método $A B C$ aloca os custos às atividades que consomem os recursos, é possível determinar quais agregam valor às ações do ente público, possibilitando a avaliação da eficiência, a eficácia e a efetividade na aplicação desses recursos.

Para dar continuidade a esta pesquisa, sugere-se o acompanhamento do SISCUSTOS, cuja implantação foi efetivada em 2008 e também estudos de outros entes públicos de obtiveram sucesso no desenvolvimento de sistemas de custeio para 
que se possa concluir com maior nível de confiança qual o método mais adequado para o Serviço Público.

\section{REFERÊNCIAS:}

ANDRADE, Nilton de Aquino; BATISTA, Daniel Gerhard; SOUSA, Cleber Batista de. Vantagens e desvantagens da utilização do Sistema de Custeio ABC. Disponível em $<$ www.fae.edu/publicacoes/pdf/art_cie/art_37.pdf>. Acesso em: 25/fev/2008.

BRASIL. (2008a). Lei no 4.320, de 17 de março de 1964. Dispõe sobre as normas gerais de direito financeiro para elaboração e controle dos orçamentos e balanços da União, dos Estados, dos Municípios, e do Distrito Federal. Disponível em: < http://www3.dataprev.gov.br/SISLEX/paginas/42/1964/4320.htm>. Acesso em: 15/fev.

BRASIL. (2008b). Decreto-Lei n. 200, de 25 de fevereiro de 1967. Dispõe sobre a organização da administração federal, estabelece diretrizes para reforma administrativa e dá outras providências. Disponível em:< http://www81.dataprev.gov.br/SISLEX/PAGINAS/24/1967/200.htm>. Acesso em: 15/fev.

BRASIL. (2008c). Decreto n. 93.872, de 23 de dezembro de 1986. Dispõe sobre a unificação dos recursos de caixa do Tesouro Nacional, atualiza e consolida a legislação pertinente e dá outras providências. Disponível em: < http://www.planalto.gov.br/ccivil/decreto/D93872.htm>. Acesso em: 15/fev.

BRASIL. (2008d). Lei Complementar no 101, de 4 de maio de 2000. Dispõe sobre normas de finanças públicas para a responsabilidade na gestão fiscal e dá outras providências. <http://www.planalto.gov.br/CCIVIL/Leis/LCP/Lcp101.htm>. Acesso em: 10/fev.

BRASIL. (2008e). Lei Ordinária. n. 10.180, de 6 de fevereiro de 2001. Dispõe sobre organiza e disciplina os sistemas de planejamento e de orçamento federal, de administração financeira federal, de contabilidade federal e de controle interno do poder executivo federal e dá outras providências. Disponível em: < http://www010.dataprev.gov.br/sislex/paginas/42/2001/10180.htm>. Acesso em: 15/fev.

BRASIL. (2008f). Lei 10.524, de 25 de julho de 2002. Dispõe sobre Dispõe sobre as diretrizes para elaboração da Lei Orçamentária de 2003 e dá outras providências. Disponível em: <http://www010.dataprev.gov.br/sislex/paginas/42/2002/10524.htm>. Acesso em: 15/fev.

BRASIL. (2008g). Lei 10.707, de 30 de julho de 2003. Dispõe sobre as diretrizes para elaboração da Lei Orçamentária de 2004 e dá outras providências. Disponível em: <lhttp://www.planalto.gov.br/CCIVIL/Leis/2003/L10.707.htm>. Acesso em: 15/fev. 
BRASIL. (2008h). Lei 11.178, de 20 de setembro de 2005. Dispõe sobre as diretrizes para elaboração da Lei Orçamentária de 2006 e dá outras providências. Disponível em:<

http://www010.dataprev.gov.br/sislex/paginas/42/2005/11178.htm>. Acesso em: 14/fev.

CARNEIRO JUNIOR, Moacir. (2006). Análise do processo de gestão de pequenas e médias empresas competitivo-cooperativas: Estudo do Pólo Gastronômico de Santa Felicidade. (Dissertação ao Programa de Pós-graduação em Administração) - PPAD Centro de Ciências Sociais Aplicadas, Pontifícia Universidade Católica do Paraná, como requisito parcial à obtenção de grau de Mestre, Curitiba.

COMISSÃO INTERMINISTERIAL DE CUSTOS. Relatório final. Disponível em:

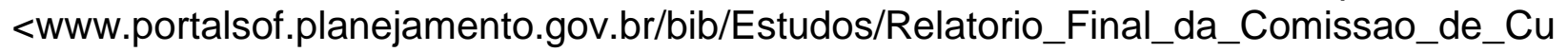
stos.pdf>. Acesso em 26/fev/2008.

MARTINS, Eliseu. (2001). Contabilidade de Custos. (8 ed.). São Paulo: Atlas.

MATTOS, José Geraldo. Custo de Produção. Disponível em: <http://www.gea.org.br/scf/aspectosteoricos.html>. Acesso em: 26/fev/2008.

MINISTÉRIO DA DEFESA/EXÉRCITO BRASILEIRO. (2007). Estágio de Custos. Curso presencial. Brasília: MINISTÉRIO DA DEFESA/EXÉRCITO BRASILEIRO.

MINISTÉRIO DA DEFESA/EXÉRCITO BRASILEIRO. Manual do Usuário. Disponível em: http://www.5icfex.eb.mil.br/Download/manual_siscustos-v\%20dez07.pdf>. Acesso em 18/fev/2008.

Portaria interministerial n. 945, de 26 de outubro de 2005. Dispõe sobre a criação de comissão para subsidiar a implantação do sistema de custos na administração pública federal. Disponível em: http://www. anasps.org.br/index.asp?id=1473\&categoria=29\&subcategoria=89>. Acesso em: $20 / \mathrm{fev} / 2008$.

Portaria do Comandante do Exército no 932, de 19 de dezembro de 2007. Aprova as Normas para o Funcionamento do Sistema. Gerencial de Custos do Exército. Disponível em: <http://www.8icfex.eb.mil.br/binfo/2007/8ICFEx_BINFO12_07.doc > Acesso em: 20/ $\mathrm{fev} / 2008$. 